\title{
Observation of aftershocks of the 2003 Tokachi-Oki earthquake for estimation of local site effects
}

\author{
Hiroaki Yamanaka, Kentaro Motoki, Kiminobu Etoh, Masanari Murayama, and Nobuhiko Komaba \\ Interdisciplinary Graduate School of Science and Engineering, Tokyo Institute of Technology, 4259 Nagatsuta, Midori-ku, \\ Yokohama, Kanagawa 226-8503, Japan
}

(Received November 30, 2003; Revised March 5, 2004; Accepted March 5, 2004)

\begin{abstract}
Observation of aftershocks of the 2003 Tokachi-Oki earthquake was conducted in the southern part of the Tokachi basin in Hokkaido, Japan for estimation of local site effects. We installed accelerographs at 12 sites in Chokubetsu, Toyokoro, and Taiki areas, where large strong motion records were obtained during the main shock at stations of the K-NET and KiK-net. The stations of the aftershock observation are situated with different geological conditions and some of the sites were installed on Pleistocene layers as reference sites. The site amplifications are investigated using spectral ratio of $S$-waves from the aftershocks. The $S$-wave amplification factor is dominant at a period of about 1 second at the site near the KiK-net site in Toyokoro. This amplification fits well with calculated 1D amplification of $S$-wave in alluvial layers with a thickness of 50 meters. In addition to the site effects, we detected nonlinear amplification of the soft soils only during the main shock. The site effects at the strong motion site of the K-NET at Chokubetsu have a dominate peak at a period of 0.4 seconds. This amplification is due to soft soils having a thickness of about 13 meters. Contrary to the results at the two areas, site effects are not significantly different at the stations in the Taiki area, because of similarity on surface geological conditions.
\end{abstract}

Key words: 2003 Tokachi-Oki earthquake, strong ground motion, aftershock observation, local site effect, site amplification, Tokachi basin.

\section{Introduction}

The 2003 Tokachi-Oki earthquake with an $\mathrm{Mj}$ of 8.0 is one of the largest earthquakes which occurred in the area in the past. A similar large earthquake with an $\mathrm{Mj}$ of 8.2 occurred in the area in 1952 (Yamanaka and Kikuchi, 2003). Due to the 1952 Tokachi-Oki earthquake, 1 to $15 \%$ of wooden houses were collapsed in the southeastern part of Hokkaido (The Special Committee for the Investigation of the TokachiOki Earthquake, 1954). In particular, a high concentration of collapsed wooden houses was observed in the area along the Tokachi river and coastal area with soft soils. Although the houses at that time were very weak (Kobayashi, 1952), it seems that the damage pattern cannot be explained without a consideration of effects of the local geological conditions. During the 2003 Tokachi-Oki earthquake, severe shaking was also experienced in the same area. This, again, suggests that local site effects are one of the important keys to understand damage distribution due to the 2003 Tokachi-Oki earthquake. Strong motion records were obtained in the KNET and KiK-net in the damage area during the earthquake. Some of the strong motion records show large peak values of ground acceleration and velocity. Although these data provide useful information on strong shaking, we cannot understand spatial distribution of strong ground motion from strong motion records at a single point in an area. Furthermore, the small number of data on subsurface structure in the

Copy right(c) The Society of Geomagnetism and Earth, Planetary and Space Science (SGEPSS); The Seismological Society of Japan; The Volcanological Society of Japan; The Geodetic Society of Japan; The Japanese Society for Planetary Sciences; TERRAPUB focal area also makes it difficult to estimate spatial variation of ground motion.

In this study, we conducted aftershock observation in three sites in the focal area of the 2003 Tokachi-Oki earthquake to estimate site amplification factors. In particular we pay attention to estimation of effects of surface geological conditions on seismic motion around strong motion stations of the K-NET and KiK-net at Toyokoro, Chokubetsu and Taiki in the southern part of the Tokachi basin in Hokkaido prefecture, Japan. These three areas are chosen, because large ground velocities were observed in the K-NET and KiK-net during the main shock.

\section{Characteristics of Strong Ground Motion dur- ing Main Shock}

In the studied areas, the two stations of the K-NET are located in Chokubetsu (HKD086) and Taiki (HKD098), and one station in Toyokoro belongs to the KiK-net (TKCH007). It is noted that strong motion records at the bottom of the borehole with a depth of about 100 meters are also available at the station. The locations of these stations are shown in Fig. 1.

The ground acceleration records at the strong motion stations are shown in Fig. 2. The peak ground acceleration (PGA) at Chokubetsu is the largest as $0.8 \mathrm{G}$ among the stations. The PGAs at the other two sites are approximately 0.4G. The PGA on the surface at Toyokoro (TKCH007) is 2.5 times as large as that at the bottom. The observed records are integrated to ground velocities as shown in Fig. 3. We used a band-pass filter with periods from 0.1 to 12 seconds 
a)
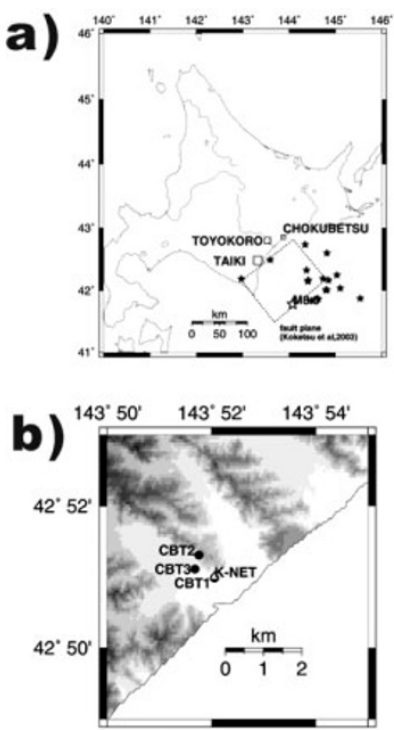

c)

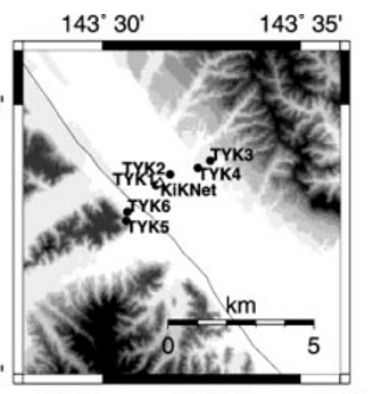

d)

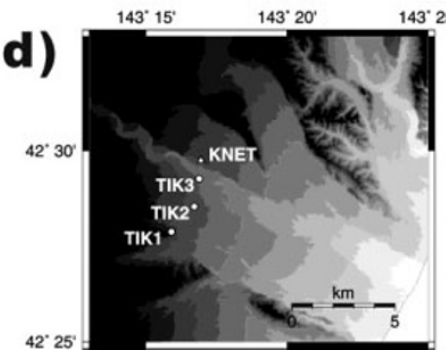

Fig. 1. Maps of locations of a) areas of investigation in this study with focal area (Kohketsu et al., 2003), and aftershock observations and strong motion stations in b) Chokubetsu, c) Toyokoro, and d) Taiki in Hokkaido, Japan.
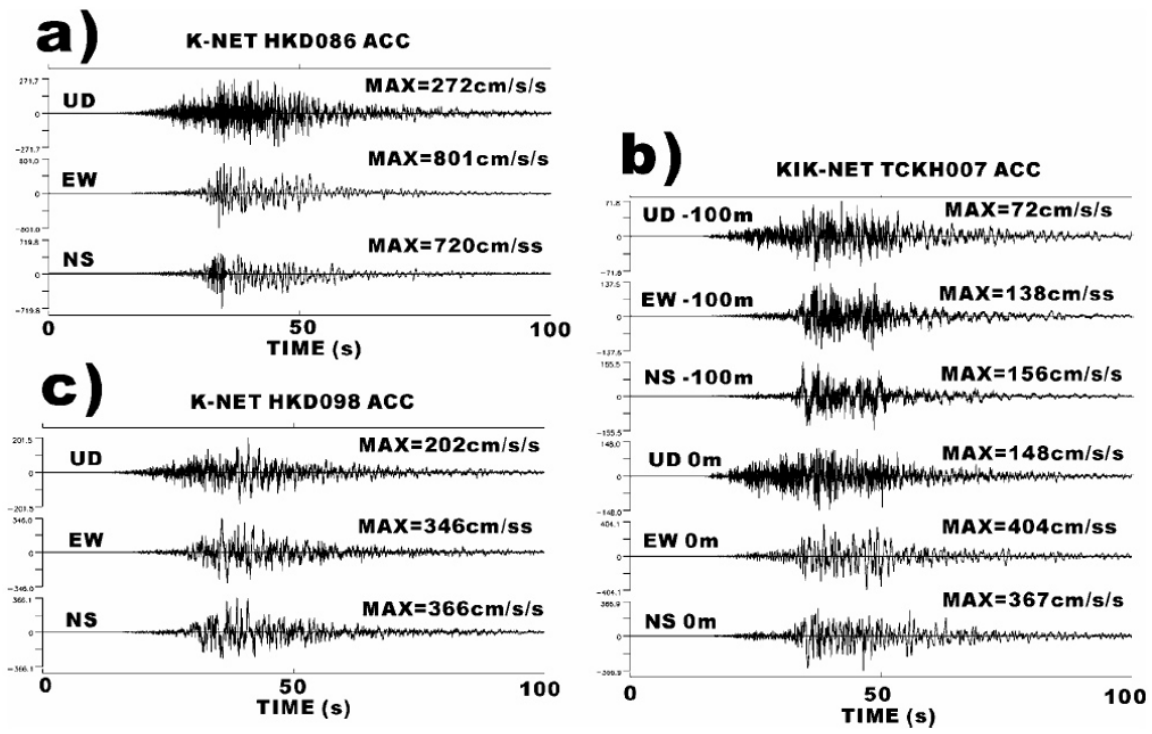

Fig. 2. Ground accelerations at strong motion stations of a) HKD086, c) HKD098 and b) TKCH07 during the 2003 Tokachi-Oki earthquake.

\section{a)}
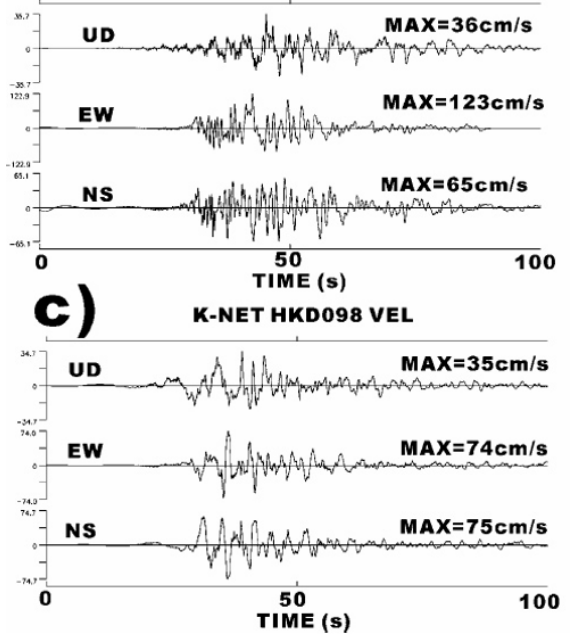

b)
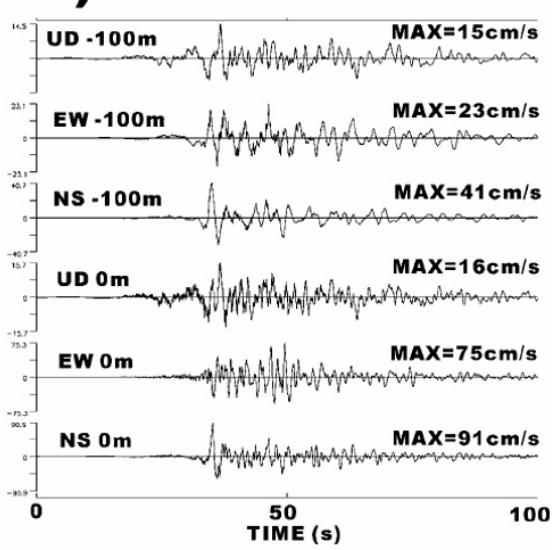

Fig. 3. Ground velocity at strong motion stations of a) HKD086, c) HKD098, b) TKCH07 during the 2003 Tokachi-Oki earthquake. All the traces are filtered in period range from 0.1 to $12 \mathrm{sec}$. 
Table 1. List of aftershock observation stations.

\begin{tabular}{|c|c|c|c|c|c|}
\hline Area & $\begin{array}{l}\text { station } \\
\text { code }\end{array}$ & Location & $\begin{array}{l}\text { Latitude } \\
\text { (deg) }\end{array}$ & $\begin{array}{l}\text { Longitude } \\
\text { (deg) }\end{array}$ & $\begin{array}{l}\text { Surface geological } \\
\text { condition }\end{array}$ \\
\hline \multirow[t]{3}{*}{ Chokubetsu } & CBT1 & Chokubetsu railway station & 42.84974 & 143.86758 & Alluvial deposits \\
\hline & CBT2 & Chokubetsu & 42.85517 & 143.86266 & Miocene mudstone \\
\hline & CBT3 & Chokubestu & 42.85184 & 143.86134 & Alluvial deposits \\
\hline \multirow[t]{6}{*}{ Toyokoro } & KYK1 & Chuoshin-machi, Toyokoro cho & 42.80843 & 143.52248 & Alluvial deposits \\
\hline & TYK2 & Chuoshin-machi, Toyokoro cho & 42.81169 & 143.52844 & Alluvial deposits \\
\hline & TYK3 & Toyokorosasada-machi, Toyokoro cho & 42.81603 & 143.54539 & Pleistocene gravel \\
\hline & TYK4 & Toyokoroasahi-machi, Toyokoro cho & 42.81375 & 143.54013 & Alluvial deposits \\
\hline & TYK5 & Moiwa, Toyokoro cho & 42.79746 & 143.51010 & Miocene mudstone \\
\hline & TYK6 & Moiwa, Toyokoro cho & 42.80014 & 143.51059 & Alluvial deposits \\
\hline \multirow[t]{3}{*}{ Taiki } & TIK1 & Taiki cemetery, Taiki cho & 42.46471 & 143.26513 & Pleistocene gravel \\
\hline & TIK2 & Furubetu, Taiki cho & 42.47579 & 143.27864 & Pleistocene gravel \\
\hline & TIK3 & Sakae-touri, Taiki cho & 42.48790 & 143.28146 & Pleistocene gravel \\
\hline
\end{tabular}

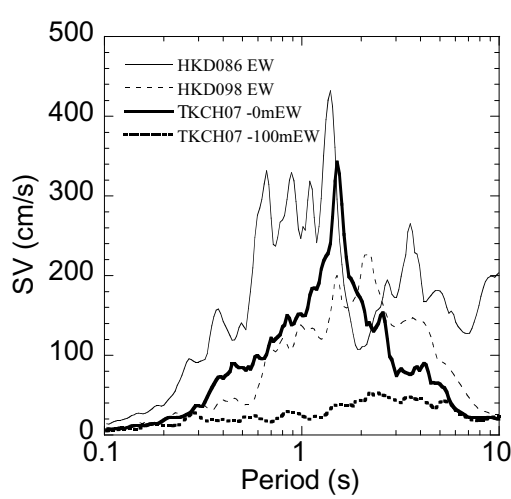

Fig. 4. Response spectra with damping of $5 \%$ for the strong motions in Fig. 2.

in the integration. The large peak ground velocity (PGV) of $123 \mathrm{~cm} / \mathrm{s}$ is obtained at Chokubetsu (HKD086). At Toyokoro (TKCH007), a large impulsive $S$-wave is observed in northsouth oriented ground velocity. The PGV at the surface is 2 to 3 times as large as those at the bottom at Toyokoro. The ground velocities at Taiki (HKD098) are mainly composed of three impulsive phases that probably correspond to $S$-waves from three major asperities on the fault (Koketsu et al., 2003).

We compare response spectra for these strong motion records. Figure 4 shows pseudo spectral velocity (PSV in the following) with a damping of 5\% for the strong motion records. The PSV at Chokubetsu (HKD086) is the largest at entire periods among the response spectra and significantly large in the long-period range, too. This might be caused by liquefaction that occurred near the strong motion station. A significantly dominant peak at a period of 1.3 seconds can be seen in the PSV at Toyokoro (TKCH007) indicating strong local site effects. On the other hand, the peak of the PSV at Taiki (HKD098) at period of 2 seconds may be understood as effects of deep sedimentary layers whose thicknesses are $1.8 \mathrm{~km}$ to the basement with an $S$-wave velocity of about 3 $\mathrm{km} / \mathrm{s}$ (Matsushima et al., 1991), because low velocity layers near the surface are not so thick.

\section{Aftershock Observation}

The aftershock observation was conducted from the 27th to 29th, September, 2003 in the Toyokoro, Chokubetsu and Taiki areas in the southeastern part of the Tokachi basin. The

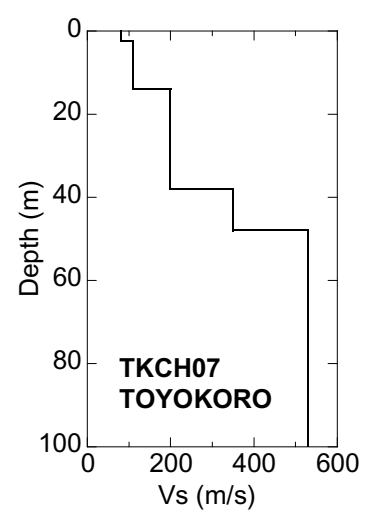

Fig. 5. $S$-wave profile at strong motion site of the KiK-net in Toyokoro. locations of the temporary stations in the aftershock observation are shown in Fig. 1. Details for the observations can be also seen in Table 1 together with geological classifications from geological maps (Geological Survey Japan, 2003).

Six stations were installed in Toyokoro. One of the stations, TYK1, is located near the strong motion station of the KiK-net (TKCH07). Shallow $S$-wave profile at the KiK-net station is available as shown in Fig. 5. The depth to the firm soils having an $S$-wave velocity of $530 \mathrm{~m} / \mathrm{s}$ is about 50 meters. TYK5 is located at the foot of a hill that is covered with Miocene mudstone. This station can be regarded as reference station in the following analysis. TYK3 is also located on firm layers in Pleistocene terrace at the other side of the Tokachi river. The other stations are located in the alluvial valley along the river.

In the Chokubetsu area, three stations were served in the aftershock observation as shown in Fig. 1(b). CBT1 is located near the strong motion station of the K-NET (HKD086), where the $P G V$ is $123 \mathrm{~cm} / \mathrm{s}$ during the main shock. Although CBT1 and CBT3 are located on the alluvial layers, damage of wooden houses was more severe around CBT1 than around CBT3. The CBT2 station was installed on the hill covered with Miocene mudstone.

In the Taiki area, three stations were temporarily deployed with similar geological conditions in Pleistocene age. One of the stations, named TIK1, is located in a hilly zone and is used as a reference station in the following analysis. It is noted that the station of the K-NET (HKD098) is located at a distance of about $1 \mathrm{~km}$ in the north of TIK3. The firm soils 
Table 2. List of earthquakes.

\begin{tabular}{|c|c|c|c|c|c|c|c|c|}
\hline No & $\begin{array}{c}\text { Date } \\
(\mathrm{DD} / \mathrm{MM} / \mathrm{YY})\end{array}$ & $\begin{array}{c}\text { Origin time } \\
\text { (HH:MM:SS) }\end{array}$ & $\begin{array}{c}\text { Latitude } \\
\text { (deg) }\end{array}$ & $\begin{array}{c}\text { Longitude } \\
\text { (deg) }\end{array}$ & $\begin{array}{l}\text { Dep } \\
(\mathrm{km})\end{array}$ & $\mathrm{Mj}$ & Obs. area & $\begin{array}{c}\text { Max PGA } \\
(\mathrm{cm} / \mathrm{s} / \mathrm{s})\end{array}$ \\
\hline EQ01 & $27 / 09 / 03$ & $17: 06: 21.6$ & 42.733 & 144.346 & 59.2 & 5.2 & Chokubetsu & 85.13 \\
\hline EQ02 & $27 / 09 / 03$ & $19: 50: 23.8$ & 41.840 & 144.490 & 24.5 & 4.5 & Chokubetsu & 1.54 \\
\hline EQ03 & $27 / 09 / 03$ & $22: 13: 53.8$ & 42.149 & 144.401 & 25.4 & 4.2 & Chokubetsu & 2.51 \\
\hline EQ04 & $28 / 09 / 03$ & 01:07:40.6 & 42.328 & 144.376 & 48.9 & 5.1 & Chokubetsu, Toyokoro & 25.27 \\
\hline EQ05 & $28 / 09 / 03$ & $07: 23: 24.5$ & 42.188 & 142.973 & 50.7 & 5.2 & Chokubetsu, Toyokoro & 21.21 \\
\hline EQ06 & $28 / 09 / 03$ & 08:04:40.7 & 42.193 & 144.731 & 28.6 & 5.1 & Chokubetsu, Toyokoro & 12.15 \\
\hline EQ07 & $28 / 09 / 03$ & $11: 59: 11.8$ & 42.010 & 144.818 & 34.0 & 4.3 & Chokubetsu & 1.86 \\
\hline EQ08 & $28 / 09 / 03$ & $13: 17: 55.7$ & 42.601 & 144.816 & 48.2 & 5.5 & Chokubetsu & 12.21 \\
\hline EQ09 & $28 / 09 / 03$ & $15: 23: 12.59$ & 42.165 & 144.414 & 34.3 & 3.8 & Chokubetsu & 2.35 \\
\hline EQ10 & $28 / 09 / 03$ & $19: 31: 27.49$ & 42.247 & 145.033 & 24.3 & 4.2 & Chokubetsu & 1.79 \\
\hline EQ11 & $28 / 09 / 03$ & 20:08:48.9 & 42.038 & 145.106 & 25.3 & 4.3 & Chokubetsu & 1.54 \\
\hline EQ12 & $28 / 09 / 03$ & $23: 13: 52.92$ & 42.008 & 144.794 & 34.6 & 4.9 & Toyokoro, Taiki & 2.77 \\
\hline EQ13 & $29 / 09 / 03$ & 01:50:54.6 & 41.874 & 145.537 & 18.5 & 5.5 & Toyokoro, Taiki & 4.09 \\
\hline EQ14 & $29 / 09 / 03$ & $05: 57: 42.9$ & 41.867 & 144.631 & 37.0 & 4.7 & Toyokoro, Taiki & 3.31 \\
\hline EQ15 & $29 / 09 / 03$ & 06:29:44.1 & 42.165 & 144.850 & 27.1 & 5.0 & Toyokoro, Taiki & 3.47 \\
\hline EQ16 & $29 / 09 / 03$ & $10: 10: 43.1$ & 42.492 & 143.596 & 57.1 & 4.0 & Taiki & 11.50 \\
\hline
\end{tabular}

2003 09/27 17:06 EW

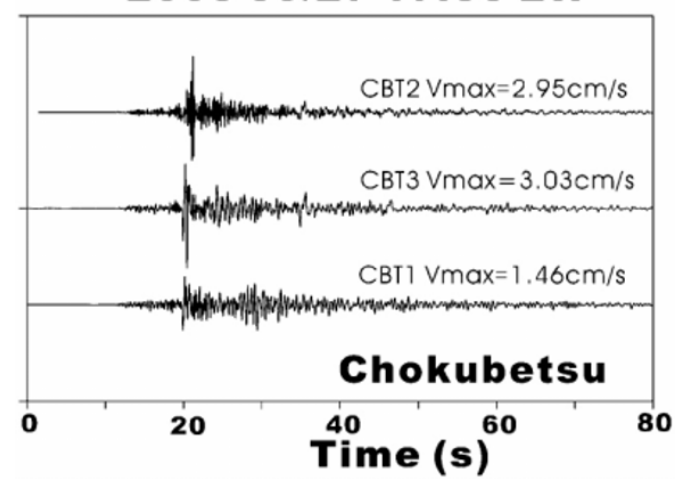

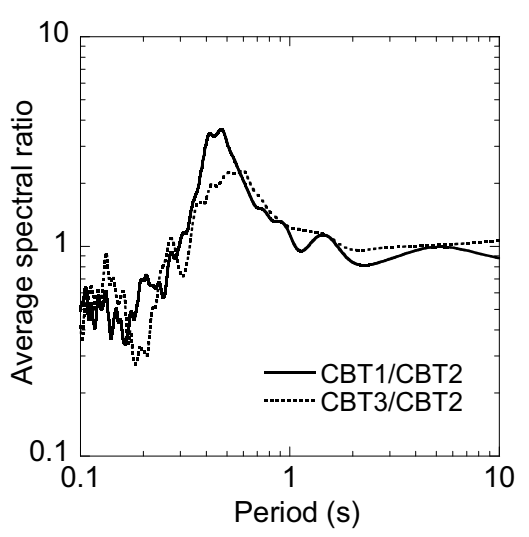

Fig. 7. Ratios of spectra of aftershocks at stations of CBT1 and CBT3 to that at reference site of CBT2. The ratios are calculated from average of $S$-wave spectra of all the records from the events in Table 2.

the events in Table 2. We used root-mean square of the two horizontal spectra to calculate the spectral ratios. The spectral ratios for the two sites in Fig. 7 exhibit similar features having peaks in a period range from 0.4 to 0.7 seconds. However, the ratio at $\mathrm{CBT} 1$ has a more dominant peak than that for CBT3, suggesting the strong site effects at CBT1.

\subsection{Toyokoro area}

The ground velocities observed in the Toyokoro area during an aftershock (EQ06) are displayed in Fig. 8. Ground velocities at the sites located at the both ends of the valley are very smaller than those in the valley. The PGV at TYK1 near the strong motion station of the KiK-net is the largest among the sites in the area. The later arriving phases are also distinct at the station, indicating strong effects of site amplification. The averaged ratios of $S$-wave spectra at the stations in the valley to that at the reference station of TYK5 are shown in Fig. 9. The spectral ratio for TYK3 on Pleistocene layers is almost flat in a period range longer than 0.3 seconds. This implies that incident $S$-wave to the soft soils of the valley is similar in the area. The ratios at the other sites have peaks at periods from 0.3 to 1 second. In particular, the longest and largest peaks at a period of 0.9 seconds can be found in the ratio for TYK2. This can be interpreted as site amplification due to sediments in the valley as explained later. significant. Ratios of $S$-wave spectra at CBT1 and CBT3 to that at CBT2 were calculated from averaging the ratios for

\section{Analysis of Observed Aftershock Records}

We selected records with a PGA of more than $1 \mathrm{~cm} / \mathrm{s} / \mathrm{s}$ at all the sites in our aftershock observation for the followin Figure 6 shows an example of the ground velocities obtained at the stations in Chokubetsu during the aftershock, EQ01. All the traces in the figure indicate the east-west component of the ground velocities filtered in a period range from 0.1 to 5 seconds. The trace at CBT2 on the hill is rich in highfrequency contents, while that for the CBT1 station is no 


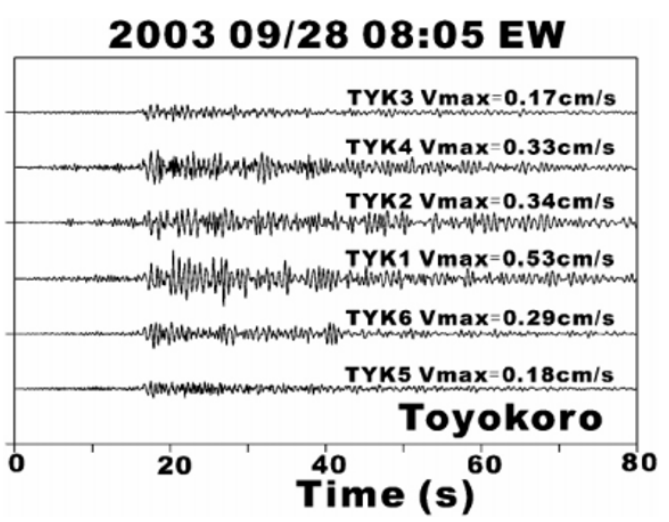

Fig. 8. Ground velocities of aftershock, EQ06, obtained in Toyokoro area. Each trace indicates velocity in the east-west direction.

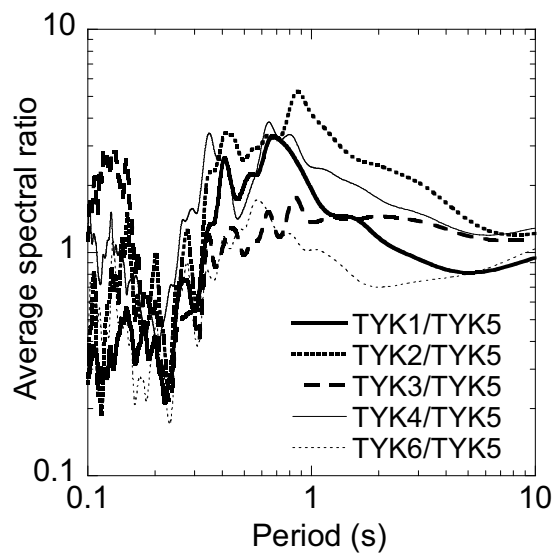

Fig. 9. Ratios of spectra of aftershocks at stations of TYK1 to TYK4 and TYK6 to that at reference site of TYK5. The ratios are calculated from average of $S$-wave spectra of all the records from the events in Table 2.

\subsection{Taiki area}

Ground velocity observed in the Taiki area during an aftershock (EQ13) is displayed in Fig. 10. The averaged spectral ratios of $S$-waves at TIK 2 and TIK 3 to that at TIK 1 are depicted in Fig. 11. As expected from the geological conditions shown in Table 1, the characteristics of the ground motions are very similar at periods from 0.2 to 2 seconds. This suggested that the area is similarly shaken during the main shock. The area is mainly covered with Miocene gravel; this surface geological condition supports the interpretation.

\section{Site Amplifications}

It is suggested from the above spectral ratios that the site amplification is significant in the Toyokoro and Chokubetsu areas. Unfortunately, an $S$-wave velocity for the soft soils is available only to a depth of 11 meters at the strong motion station of the K-NET in Chokubetsu with an $S$-wave velocity of $130 \mathrm{~m} / \mathrm{s}$ at the bottom. Since the $S$-wave velocity near the surface is similar to that at the bottom, the profile is not sufficient to calculate site amplification factors for the Chokubetsu area. Instead of calculating amplification, we can estimate a total thickness of the soft soils. Considering that the peak period of the spectral ratio at CBT1 is 0.4 seconds, the thickness of the soils is estimated to be 13 meters with an assumption of the existence of a single layer
2003 09/29 01:51 EW

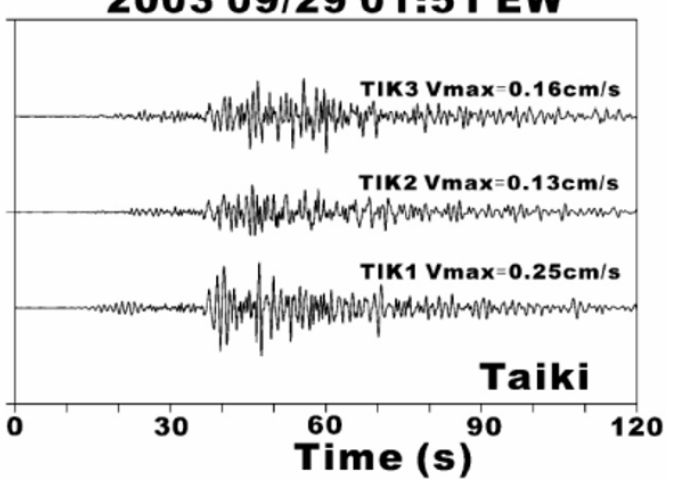

Fig. 10. Ground velocities of aftershock, EQ13, obtained in Taiki. Each trace indicates velocity in the east-west direction.

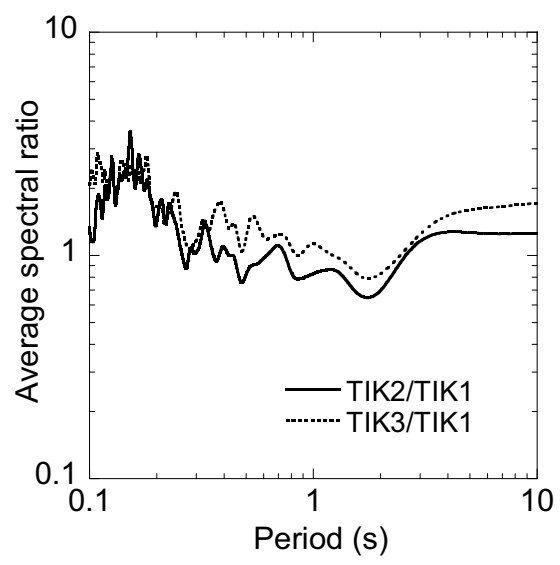

Fig. 11. Ratios of spectra of aftershocks at stations of TIK2 and TIK3 to that at reference site of TIK1. The ratios are calculated from average of $S$-wave spectra of all the records from the events in Table 2.

having an $S$-wave velocity of $130 \mathrm{~m} / \mathrm{s}$.

We, next, discuss the site amplification factors in the Toyokoro area. We calculated amplification of $S$-wave propagating vertically in the subsurface structural model in Fig. 5. The amplification factor estimated from the aftershock records observed at TYK1 is compared with the calculated one in Fig. 12 by assuming motion whose amplitude is half of the ground motion observed at TYK5 as an incident wave. The calculated and observed amplifications agree with each other. The slight difference in the peak periods is probably due to the differences in subsurface structures between the two sites, because the two sites are apart with a distance of about 150 meters.

We also investigate the amplification factors using the records obtained at the surface and bottom of the borehole at the strong motion station of the KiK-net. We selected three events with different magnitudes. They are the main shock, the largest aftershock with an $\mathrm{Mj}$ of 7.0 and the aftershock EQ01 with an $\mathrm{Mj}$ of 5.2. The PGAs for the records at the surface are 404, 67.1 and $6.6 \mathrm{~cm} / \mathrm{s} / \mathrm{s}$, respectively. The spectral ratios between the surface and the bottom of the bore hole are calculated using the observed records with a time window of 20.48 seconds starting from the onset time of initial $S$-wave. Figure 13 shows the spectral ratios together with the theoretical spectral ratio between the two points for vertically prop- 


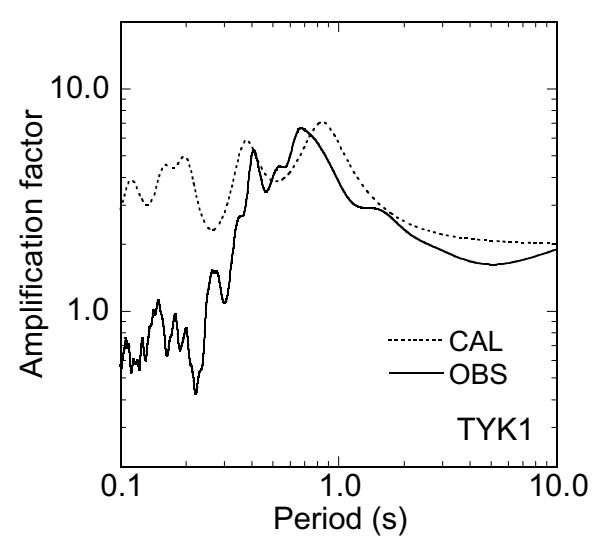

Fig. 12. Comparison of spectral ratio estimated from aftershock recodes at TYK1 and TYK5 in Toyokoro (see Fig. 9) with calculated one for the $S$-wave model in Fig. 5.

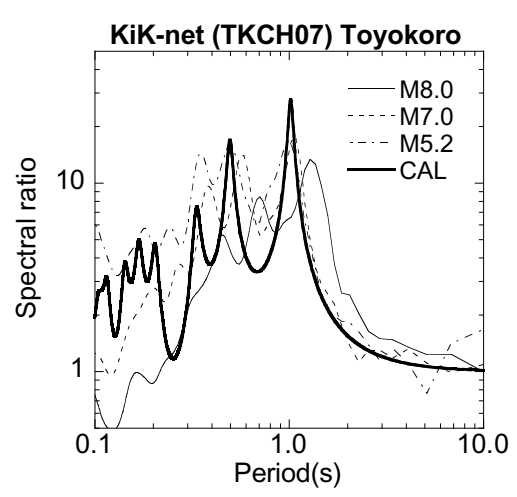

Fig. 13. Comparison of spectral ratios between records at the surface and bottom of the bore hole at station of TKCHO7 of the KiK-net in Toyokoro from main shock and aftershocks with calculated transfer function for the $S$-wave in model in Fig. 5.

agating $S$-wave in the subsurface structural model in Fig. 5. The ratios for the aftershocks fit well with the calculated ratio. In particular, the first and second peaks at periods of 1.0 and 0.5 seconds are well explained with the $1 \mathrm{D}$ propagation of $S$-wave. However, the calculated spectral ratio cannot explain the peaks of the observed ratio for the main shock. In addition to the shift of the peak period from 1.0 to $1.3 \mathrm{sec}$ onds, it is noted that the short-period amplification is reduced during the main shock. Very soft soils near the surface usually lessen their rigidity during strong shaking, because of non-linear effects (e.g., Mirdorikawa, 1993). Since the lowvelocity layers with a thickness of about 15 meters are seen in the $S$-wave profile at the station, the shifted peak periods can probably be caused by the effects of non-linear behavior of the soils.

\section{Conclusions}

We conducted observation of aftershocks of the 2003 Tokachi-Oki earthquake in the Chokubetsu, Toyokoro, and Taiki areas in the southern part of the Tokachi basin in order to estimate effects of local geological conditions on strong ground motion. In particular, we focused on the site effects at and near the strong motion sites in the areas where large strong motion records were obtained during the main shock. Accelerometers were temporarily installed at 3 to 6 sites with different surface geological conditions in each area. The spectral ratios of $S$-waves at the soft soil sites to that at the reference sites on firm layers were investigated. The $S$-wave amplification factor is dominant at about 1 second near the strong motion station of the KiK-net in Toyokoro. It is concluded from the comparison between the calculated 1D amplification of $S$-wave and the observed spectral ratios that the alluvial layers with a thickness of 50 meters are responsible for the amplification. This suggests that $1 \mathrm{D}$ amplifications for the shallow soils must be considered in estimating spatial distribution of strong motion due to the main shock. In addition to the effects, we detected a nonlinear amplification of the soft soils only during the main shock. This effect should be also included in strong motion estimation. The site effects at the strong motion site of the K-NET at Chokubetsu have a dominant peak at periods of 0.4 seconds. We interpret that this amplification is due to the soft soils having a thickness of about 13 meters. This dominant peak can be seen not only at the strong motion site but also at the other site in the Chokubetu area. Contrary to the results at these two areas, the site effects are not significantly different from each other at the stations in the Taiki area, because of similar favorable geological conditions.

Acknowledgments. We thank Horoshi Kagami at Hokkaido University for information about earthquake damage. Comments from anonymous reviewers are helpful to improve the manuscript. The strong motion data, velocity profiles and event information used in this study are provided by the K-NET and KiK-net of the National Research Institute for Earth Science and Disaster Prevention, and by Japan Meteorological Agency. This study supported by Grantin-Aid for General Scientific Research (\#14205081) and Special Project for Earthquake Disaster Mitigation in Urban Areas of the Ministry of Education, Science and Culture, Japan. Some of the figures in this paper were made using GMT (Wessel and Smith, 1991).

\section{References}

Geological Survey of Japan, Digital geological maps of Japan 1:200,000, South Hokkaido, CD-ROM, 2003.

Kobayashi, H., Damage of building in southern Hokkaido by earthquake of March 4, 1952, Zisin (Jour. Seism. Soc. Japan), 5, 151157, 1952 (in Japanese with English abstract).

Koketsu, K., Y. Yamanaka, K. Hikima, M. Kikuchi, T. Furumura and K. Hatayama, The 2003 Tokachi Oki, Japan, earthquake: Source process and strong ground motions, EOS Trans. AGU, 84(46), Fall Meet. Suppl., Abstract S52L-02, 2003.

Matsushima, T., T. Koyanagi, H. Okada, T. Moriya, T. Sasatani, K. Miyakoshi, M. Ikeda, S. Ling, An exploration method using microtremors (7)-Deep geological structures in the Tokachi basin and their effects on seismic motion-, Proceedings of the 85th SEGJ (Society of Exploration Geophysicists of Japan) conference, 264-269, 1991 (in Japanese).

Midorikawa, S., Nonlinearity of site amplification during strong ground shaking, Zisin (Jour. Seism. Soc. Japan), 46, 207-216, 1993 (in Japanese with English abstract).

The Special Committee for the Investigation of the TOKACHI-Oki Earthquake, Report on the Tokachi-Oki earthquake Hokkaido, Japan, March 1952, pp. 1018, 1954 (in Japanese)

Wessel, P. and W. H. F. Smith, Free software helps map and display data, EOS Trans. AGU., 72, 441, 445-446, 1991.

Yamanaka, Y. and M. Kikuchi, Source process of the recurrent Tokachioki earthquake on September 26, 2003, inferred from teleseismic body waves, Earth Planets Space, 55, e21-e24, 2003.

H. Yamanaka (e-mail: yamanaka@depe.titech.ac.jp), K. Motoki, K. Etoh, M. Murayama, and N. Komaba 